PNNL-19169

(1/,

Prepared for the U.S. Department of Energy

under Contract DE-AC05-76RL01830

\title{
NW-MILO Acoustic Data Collection
}

\author{
S. Matzner A. Maxwell \\ J. Myers M. Jones
}

February 2010

Pacific Northwest

NATIONAL LABORATORY 


\title{
DISCLAIMER
}

This report was prepared as an account of work sponsored by an agency of the United States Government. Neither the United States Government nor any agency thereof, nor Battelle Memorial Institute, nor any of their employees, makes any warranty, express or implied, or assumes any legal liability or responsibility for the accuracy, completeness, or usefulness of any information, apparatus, product, or process disclosed, or represents that its use would not infringe privately owned rights. Reference herein to any specific commercial product, process, or service by trade name, trademark, manufacturer, or otherwise does not necessarily constitute or imply its endorsement, recommendation, or favoring by the United States Government or any agency thereof, or Battelle Memorial Institute. The views and opinions of authors expressed herein do not necessarily state or reflect those of the United States Government or any agency thereof.

\author{
PACIFIC NORTHWEST NATIONAL LABORATORY \\ operated by \\ BATTELLE \\ for the \\ UNITED STATES DEPARTMENT OF ENERGY \\ under Contract DE-AC05-76RL01830
}

Printed in the United States of America
Available to DOE and DOE contractors from the Office of Scientific and Technical Information,
P.O. Box 62, Oak Ridge, TN 37831-0062;
ph: (865) 576-8401
fax: $(865)$ 576-5728
email: reports@adonis.osti.gov

\begin{abstract}
Available to the public from the National Technical Information Service, U.S. Department of Commerce, 5285 Port Royal Rd., Springfield, VA 22161 ph: (800) 553-6847 fax: $(703) 605-6900$ email: orders@ntis.fedworld.gov online ordering: http://www.ntis.gov/ordering.htm
\end{abstract}

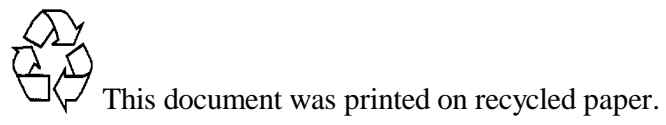


PNNL-19169

\title{
NW-MILO Acoustic Data Collection
}

\author{
S. Matzner A. Maxwell
}

J. Myers M. Jones

February 2010

Prepared for

the U.S. Department of Energy

under Contract DE-AC05-76RL01830

Pacific Northwest National Laboratory

Richland, Washington 99352 



\section{Executive Summary}

There is an enduring requirement to improve our ability to detect potential threats and discriminate these from the legitimate commercial and recreational activity ongoing in the nearshore/littoral portion of the maritime domain. The Northwest Maritime Information and Littoral Operations (NW-MILO) Program at PNNL's Coastal Security Institute in Sequim, Washington is establishing a methodology to detect and classify these threats - in part through developing a better understanding of acoustic signatures in a near-shore environment.

The purpose of the acoustic data collection described here is to investigate the acoustic signatures of small vessels. The data is being recorded continuously, 24 hours a day, along with radar track data and imagery. The recording began in August 2008, and to date the data contains tens of thousands of signals from small vessels recorded in a variety of environmental conditions. The quantity and variety of this data collection, with the supporting imagery and radar track data, makes it particularly useful for the development of robust acoustic signature models and advanced algorithms for signal classification and information extraction.

The underwater acoustic sensing system is part of a multi-modal sensing system that is operating near the mouth of Sequim Bay. Sequim Bay opens onto the Straight of Juan de Fuca, which contains part of the border between the U.S. and Canada. Table 1 lists the specific components used for the NW-MILO system. The acoustic sensor is a hydrophone permanently deployed at a mean depth of about 3 meters. In addition to a hydrophone, the other sensors in the system are a marine radar, an electro-optical (EO) camera and an infra-red (IR) camera. The radar is integrated with a vessel tracking system (VTS) that provides position, speed and heading information. The data from all the sensors is recorded and saved to a central server.

The data has been validated in terms of its usability for characterizing the signatures of small vessels. The sampling rate of $8 \mathrm{kHz}$ and low pass filtering to $2 \mathrm{kHz}$ results in an alias-free signal in the frequency band that is appropriate for small vessels. Calibration was performed using a Lubell underwater speaker so that the raw data signal levels can be converted to sound pressure. Background noise is present due to a nearby pump and as a result of tidal currents. More study is needed to fully characterize the noise, but it does not pose an obstacle to using the acoustic data for the purposes of vessel detection and signature analysis.

The detection range for a small vessel was estimated using the calibrated voltage response of the system and a cylindrical spreading model for transmission loss. The sound pressure of a typical vessel with an outboard motor was found to be around $140 \mathrm{~dB} \mu \mathrm{Pa}$, and could theoretically be detected from $10 \mathrm{~km}$ away. In practical terms, a small vessel could reliably be detected from 3 $5 \mathrm{~km}$ away.

The data is archived in netCDF files, a standard scientific file format that is "self describing". This means that each data file contains the metadata - timestamps, units, origin, etc. - needed to make the data meaningful and portable. Other file formats, such as XML, are also supported. A visualization tool has been developed to view the acoustic data in the form of spectrograms, along with the coincident radar track data and camera images. 
Table 1. NW-MILO Sensors and Hardware

\begin{tabular}{ll}
\hline Item & Model \\
\hline Hydrophone & Benthos AQ-1 \\
Preamplifier & Benthos AQ-201 \\
Signal conditioning board & Custom \\
Data aquisition board & MCC DAQ 1608HS \\
Marine radar & Furuno ARPA 2117 \\
Vessel tracking software & Transas NaviMonitor \\
EO camera & IQeye Sentinel 855 \\
IR camera & Axsys FieldPro5X \\
Calibration source & Lubell 9162 speaker
\end{tabular}




\section{Acknowledgments}

Financial support was provided by the U.S. Department of Energy under Contract DE-AC05-76RL01830. 



\section{Abbreviations and Acronyms}

ABBREV DEFINITION

CSI Coastal Security Institute

DAQ data acquisition

EO electro-optical

FFT Fast Fourier Transform

fps frames per second

IR infrared

NW-MILO Northwest Maritime Information and Litoral Operations

PNNL Pacific Northwest National Laboratory

ppt parts per thousand

RMS root mean square

RPM rotations per minute

RVR receive voltage response

SL spectral level

SPL sound pressure level

STFT short time Fourier transform

TB terrabytes

TL transmission loss

TVR transmit voltage response

VTS vessel tracking system 



\section{Contents}

Executive Summary . . . . . . . . . . . . . . . . . iii

Acknowledgments ......................... . . . . .

Abbreviations and Acronyms . . . . . . . . . . . . . . . vii

1.0 Introduction $\ldots \ldots \ldots \ldots \ldots \ldots \ldots \ldots \ldots$

1.1 Underwater Acoustic Data Collection . . . . . . . . . . . . . . . . . . . 1.1

1.2 Goals of This Report $\ldots \ldots \ldots \ldots$. . . . . . . . . . . . . . . 1.1

2.0 Underwater Acoustic Sensing System ～. . . . . . . . . . . . . . . . . . . . . 2.1

2.1 Measurement Hardware . . . . . . . . . . . . . . . . . . . . . . 2.1

2.2 Data Recording Software . . . . . . . . . . . . . . . . . . . . 2.4

2.3 Supporting Data and Visualization Tools $\ldots \ldots \ldots \ldots \ldots$

2.3 .1 Radar Tracks . . . . . . . . . . . . . . . . . . . . . . 2.4

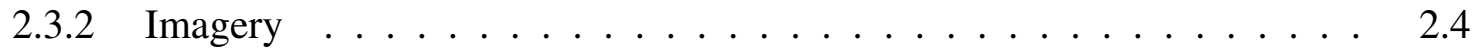

2.3 .3 Visualization Tools . . . . . . . . . . . . . . . . . . . . . 2.4

3.0 Data Validation . . . . . . . . . . . . . . . . . . . . . . . . . . . . . 3.1

3.1 System Calibration $\ldots \ldots \ldots \ldots \ldots \ldots$

3.2 Background Noise $\ldots \ldots \ldots \ldots . \ldots \ldots$

3.3 Underwater Sound Propagation $\ldots \ldots . . \ldots . \ldots . \ldots$

3.4 Detection Range . . . . . . . . . . . . . . . . . . . . . 3.7

4.0 Conclusions and Discussion $\ldots \ldots \ldots$

Appendix A - Data Acquisition System Schematic . . . . . . . . . . . . . . . . . A.1

Appendix B - Data File Formats . . . . . . . . . . . . . B.1 


\section{Figures}

$2.1 \quad$ Sequim Bay. . . . . . . . . . . . . . . . . . . . . . 2.1

$2.2 \quad$ Signal acquisition chain. . . . . . . . . . . . . . . . . . 2.2

2.3 Packaged hydrophones. . . . . . . . . . . . . . . . . . . . . . 2.2

$2.4 \quad$ Input and filtering schematic. $\ldots \ldots \ldots \ldots \ldots \ldots$

2.5 Output driver schematic. . . . . . . . . . . . . . . . . 2.3

2.6 Antialiasing circuit $\ldots \ldots \ldots \ldots \ldots \ldots \ldots \ldots$

$2.7 \quad$ ViewData visualization tool. . . . . . . . . . . . . . . . . . . . 2.5

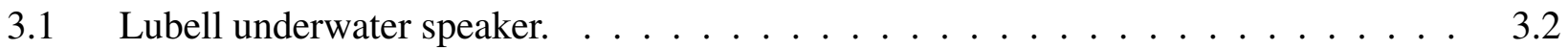

$3.2 \quad$ PNNL research vessel used for test. . . . . . . . . . . . . . . . . . . 3.2

$3.3 \quad$ Calibration test data $\ldots \ldots \ldots \ldots \ldots \ldots \ldots \ldots$

3.4 Pump noise. . . . . . . . . . . . . . . . . . . . . . 3.5

$3.5 \quad$ Noise due to strong tidal current. $\ldots \ldots \ldots \ldots \ldots$

3.6 Bathymetry of Sequim Bay. . . . . . . . . . . . . . . . . . 3.7

$\begin{array}{lll}3.7 & \text { Tranmission loss test track. } \ldots \ldots \ldots \ldots & \ldots\end{array}$

3.8 Short range transmission loss. $\ldots \ldots \ldots \ldots \ldots \ldots$ 


\section{Tables}

1 NW-MILO Sensors and Hardware . . . . . . . . . . . . . . . . . . . iv

$3.1 \quad$ Spectrogram parameters. . . . . . . . . . . . . . . . 3.1

$3.2 \quad$ Calibration Test Results $\ldots \ldots \ldots \ldots \ldots$

B.1 Raw Data File Format $\ldots \ldots \ldots \ldots \ldots \ldots \ldots$. . . . . . . . . . . . .

B.2 netCDF Data File Format $\ldots \ldots \ldots \ldots \ldots \ldots \ldots$. . . . . . . . . . . . . 



\subsection{Introduction}

Acoustic data is useful for investigating the acoustic signatures of potential threat vectors in a near-shore environment. In this report we will discuss our on-going data collection in terms of the data acquisition methodology, validation of system performance, and issues of background noise related to small boat acoustics.

\subsection{Underwater Acoustic Data Collection}

The data collection described here consists of acoustic data that is recorded continuously, 24 hours a day, along with radar track data and imagery. The collection began in August 2008, and to date totals over 2 terrabytes representing over 11,000 hours of raw recorded data. Due to the location of the sensing system between the mouth of Sequim Bay and a marina, the data contains tens of thousands of signals from small vessels. The continuous nature of the collection means that a wide variety of environmental conditions are represented. The quantity and variety of this data collection, with the supporting imagery and radar track data, makes it particularly useful in the field of acoustic signature analysis.

Vessel acoustic signature research usually relies on data collected during tests using a research vessel or on data collected by self-contained buoy systems. Buoy systems can be deployed for an extended time period on the order of days or weeks. Although this can produce a reasonable quantity of data over varying conditions, the disadvantage of this collection method is the lack of ground truth. On the other hand, experiments using a research vessel, where many of the parameters are known, are usually of very short duration and provide limited results that may not generalize to other vessels and conditions. Both of these collection methods are valuable; however, the system described here generates the type of data set that facilitates the development of robust acoustic signature models and advanced algorithms for signal classification and information extraction.

\subsection{Goals of This Report}

The goals of this report are to describe the details of the measurement and data collection system, and to present validation results that establish the usefulness of the data for the purposes of investigating small vessel signatures. 



\subsection{Underwater Acoustic Sensing System}

The underwater acoustic sensing system is part of a multi-modal sensing system that is operating at the PNNL Coastal Security Institute (CSI) in Washington, near the mouth of Sequim Bay (see Figure 2.1). The other sensors in the system are a marine radar, an EO camera and an IR camera. The radar is integrated with a vessel tracking system (VTS) that provides position, speed and heading information. The data from all the sensors is recorded and saved to a central server.

\subsection{Measurement Hardware}

The signal processing chain used for acquiring analog data in the NW-MILO program is illustrated in Figure 2.2. This example uses a hydrophone for the sensing element but it could also be used with a wide variety of sensors such as microphones or magnetometers. The primary sensing element used is the Teledyne Benthos AQ-1 hydrophone paired with an AQ-201 preamplifier. These are general purpose units typically used for seismic surveys or ocean bottom cables. Both units are packaged together as shown in Figure 2.3. The specified combined sensitivity of the pair is $-175 \mathrm{~dB}$ re $1 \mathrm{~V} / \mu \mathrm{Pa}$ (see Section 3 for the operational sensitivity test results).

After the hydrophone signals leave the water they are processed by a custom signal conditioning board. The full schematic is provided in Appendix A but individual components and descriptions are shown in Figures 2.4, 2.5 and 2.6. The final stage is the data acquisition board, the MCC-DAQ 1608HS, which offers true, simultaneous sampling at rates up to $250 \mathrm{kHz}$ for each

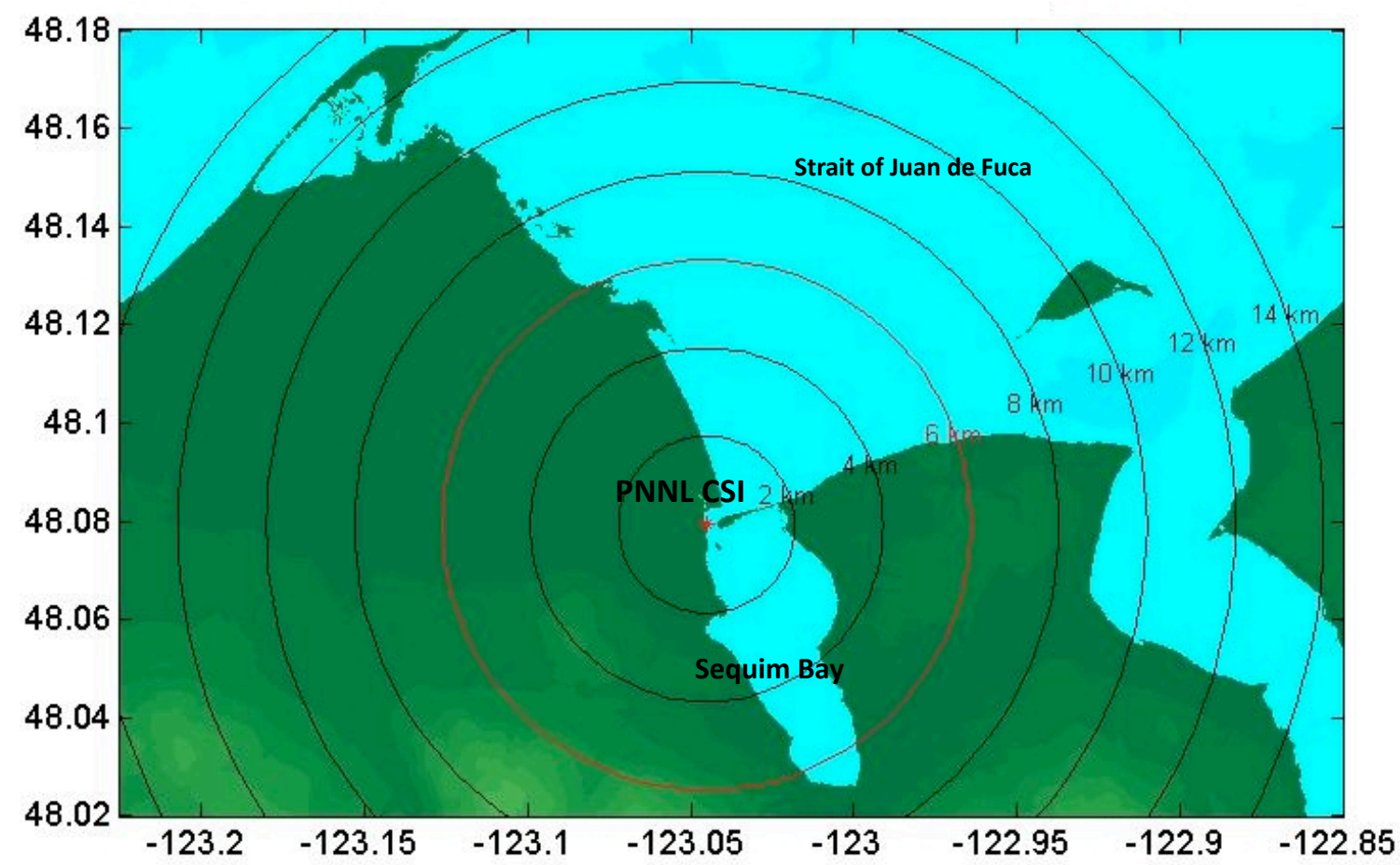

Figure 2.1. The sensing system is located near the mouth of Sequim Bay. 


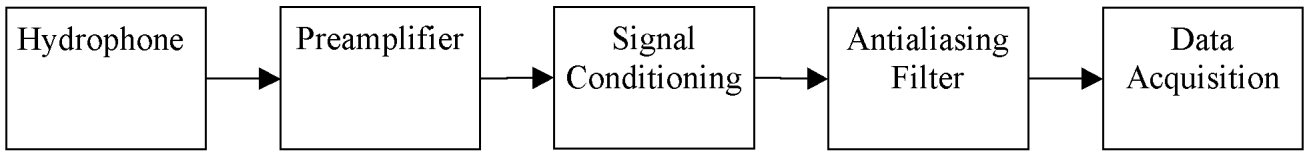

Figure 2.2. The signal acquisition chain for analog data.

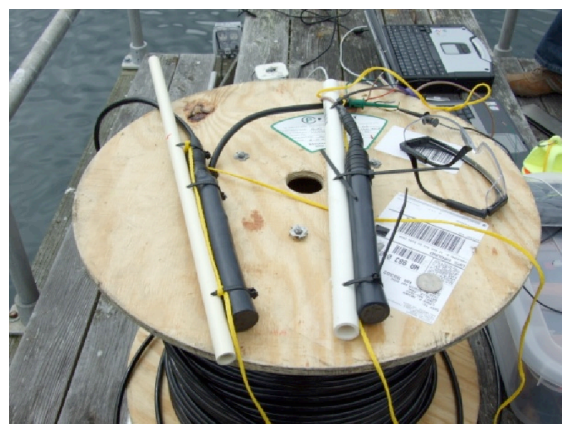

Figure 2.3. Teledyne Benthos AQ-1 hydrophone packaged with an AQ-201 preamplifier.

of the 8 available channels. The selected input range of the 1608HS is +/- 10VDC. Only one channel is currently being used on an on-going basis (for the hydrophone), which allows the other channels to be used for test signals to verify the signal processing chain, or for additional sensors.

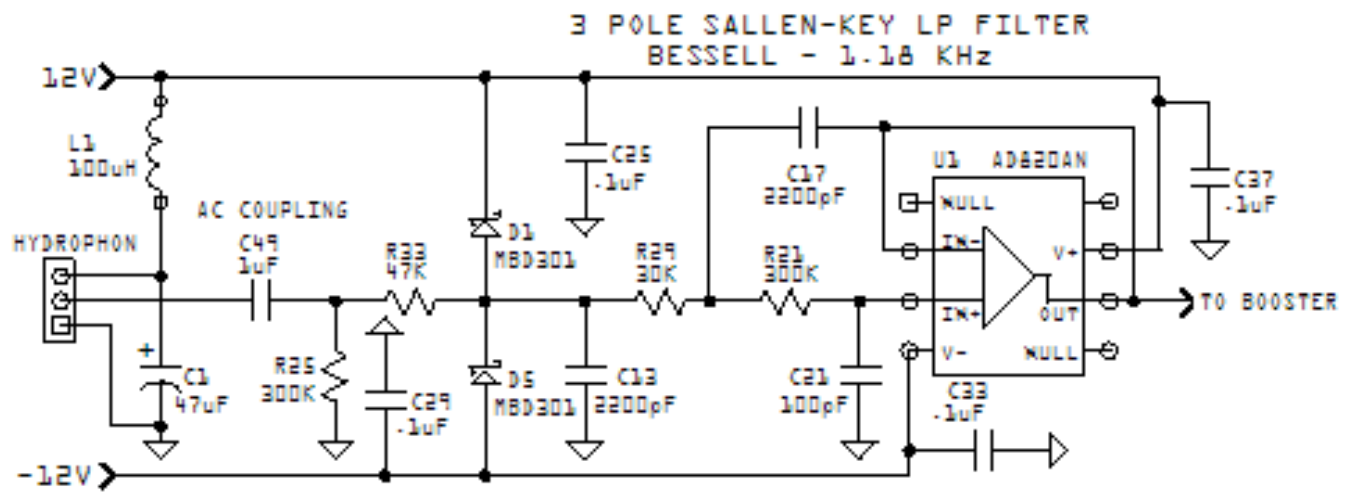

Figure 2.4. Input protection is provided by R33, D1, and D5 so that the voltage at C13 is clamped to the +/- 12 volt rails. D1 and D2 can handle $100 \mathrm{~mA}$ peak current, and $100 \mathrm{~mA}$ times $47 \mathrm{k} \Omega=4700$ volts. The filter is a 3 pole Sallen-Key with values chosen to produce a Bessel (near linear-phase) response, resulting in a flat frequency response and minimal phase distortion of the signal. The sharpest possible roll-off filter was not chosen in order to preserve signal fidelity. 


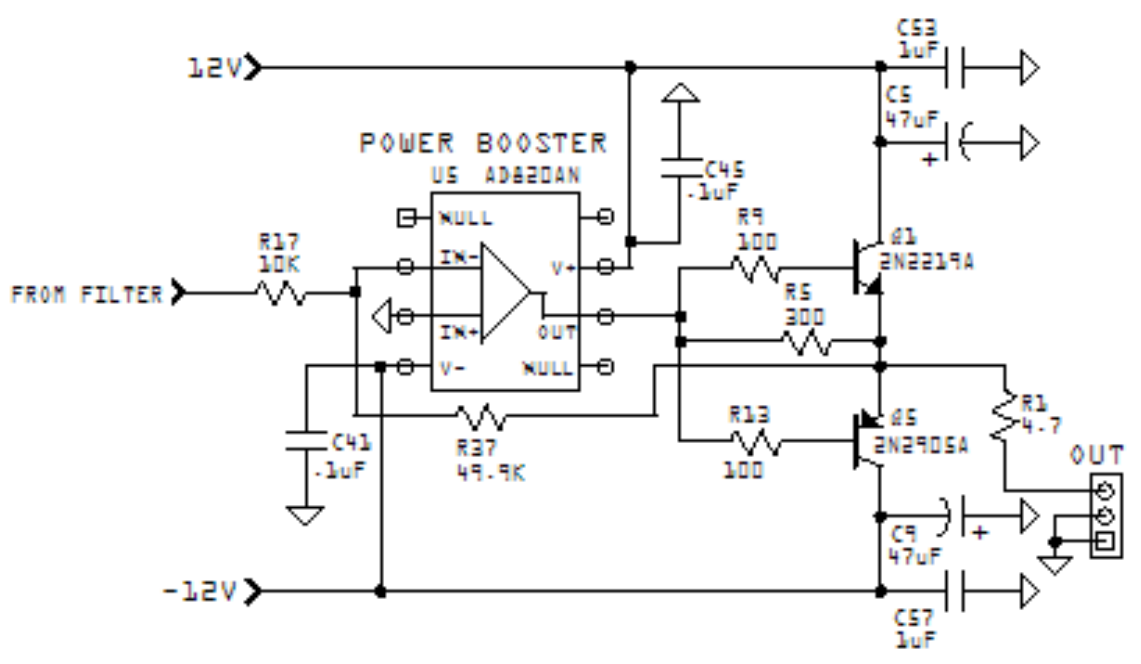

Figure 2.5. Emitter followers Q1 and Q5 provide the current boost to drive cable capacitance. $\mathrm{R} 5$ reduces the cross-over distortion as the opamp output slews between -Vbe5 and $+\mathrm{Vbe} 1$. The slew rate of the opamp $(3 \mathrm{~V} / \mu \mathrm{s})$ minimizes it for signals under $1 \mathrm{kHz}$.

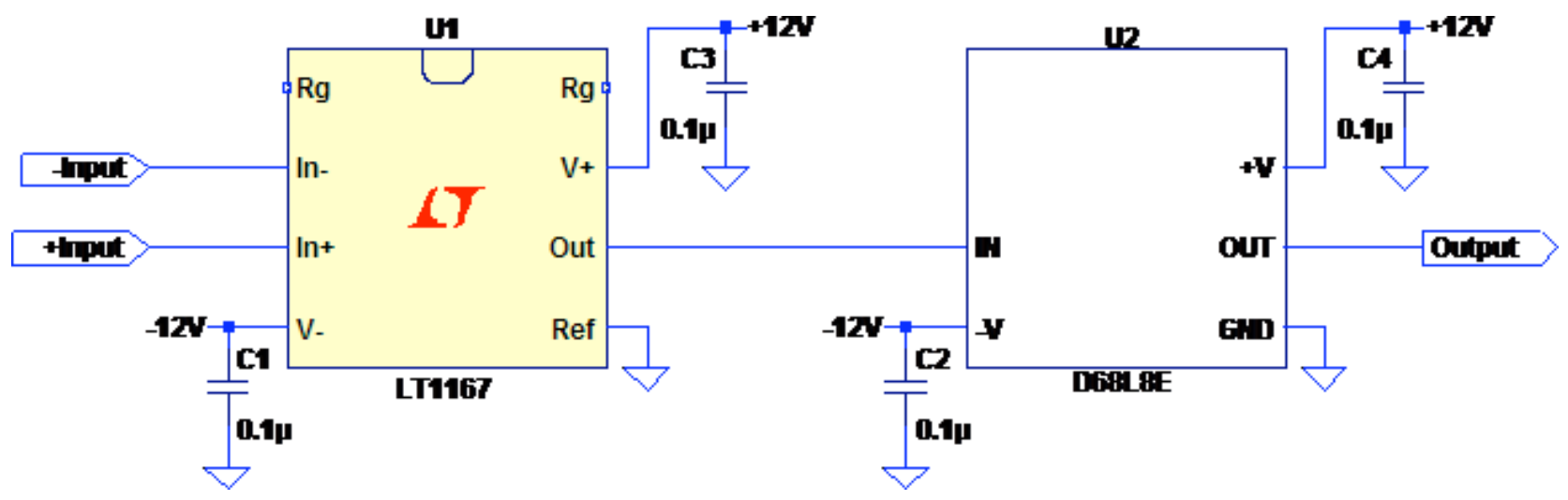

Figure 2.6. The antialiasing circuit comprises an instrumentation amplifier used as a differential receiver and a Frequency Devices 8 pole, 6 zero elliptical filter with a cutoff frequency of $2 \mathrm{kHz}$. 


\subsection{Data Recording Software}

A custom application was developed to read the raw output of the DAQ board and write the data to disk. The application provides a graphical user interface for selecting the sampling rate, labeling the recorded channels, and setting the file save interval. The format of the raw data files is given in Table B.1.

The data is also archived in netCDF files, with the structure described in Table B.2. The advantage of netCDF is that it is a standard scientific file format and is "self describing". This means that each data file contains the metadata - timestamps, units, origin, etc. - needed to make the data meaningful and portable. Other file formats, such as XML, are also supported.

\subsection{Supporting Data and Visualization Tools}

\subsubsection{Radar Tracks}

The radar track data provides vessel speed and heading along with track waypoints at $1 \mathrm{sec}$. intervals. The speed of a vessel affects the acoustic signature in that a greater engine RPM will produce a higher fundamental frequency, although the relationship between RPM and speed depends on the gear ratio. The speed and angle of approach affect the time-duration of the broadband swath that is characteristic of acoustic data in the presence of a moving vessel. Consequently, the radar track data provides important ground truth that is useful for comparing acoustic signature models to actual data.

\subsubsection{Imagery}

Camera images are saved for detected acoustic events. The video frames from the cameras are captured continuously at a combined rate of approximately $6 \mathrm{fps}$ and saved as jpeg files in a temporary directory on the server. Three days of images are available at any given time; images older than three days are deleted. Periodically, a script processes the last hour's acoustic data in order to detect the signals of vessels. A detected signal is called an event, which has a start time and an end time. For each event, all the captured images that correspond to the time of the event are moved to permanent storage. Imagery is a source of ground truth from which a vessel's size, hull style and engine type can be estimated.

\subsubsection{Visualization Tools}

A visualization tool has been developed to view the acoustic data in the form of spectrograms, along with the coincident radar track data and camera images (see Figure 2.7). The user can select a time period of interest and then display all the radar tracks and detected events (see Section 2.3.2) from that time period. The radar tracks are plotted on the map and listed by ID in the main window. When a track is selected in the list, it is drawn in red on the map and the summary information for the track is shown. The detected events are listed by start time; when an event in the list is selected, the images saved for the event are shown in the main window with a slider bar for browsing through them. 
The spectrogram tool allows the user to choose an arbitrary start time and duration for the acoustic data, which defaults to the start time of the currently selected event. The user can adjust the parameters of the spectrogram, such as window size and frequency band. The resulting image can then be saved. Using this tool ensures that the spectrogram images are consistently labeled and scaled to facilitate visual and analytic comparisons.

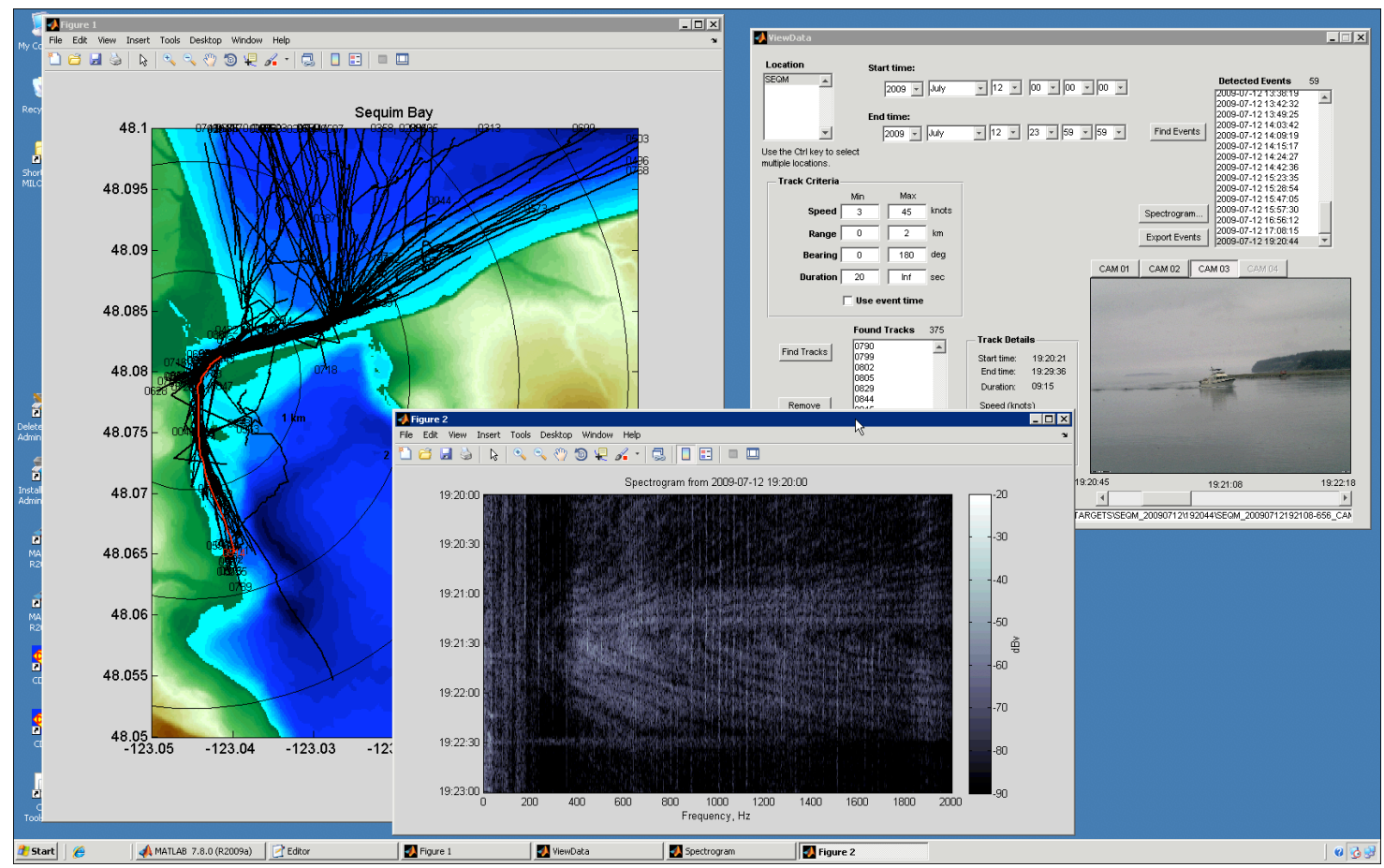

Figure 2.7. The ViewData visualization tool facilitates matching acoustic signals to vessels by displaying spectrograms, radar track data and camera images for a user-selected time period. 



\subsection{Data Validation}

In order to characterize the acoustic signatures of small vessels, a dataset must meet the following requirements.

1. The data is sampled at an adequate rate to contain the frequency band of interest, which for small vessels is up to $2 \mathrm{kHz}$.

2. The system is calibrated so that signal levels can be converted to sound pressure levels.

3. The average level of the background noise is low enough that small vessel signals can be detected and characterized in terms of harmonic content.

4. The range of the system is such that the signal from a vessel is present for an adequate amount of time to apply harmonic detection and tracking algorithms.

The last two requirements are qualitative rather than quantitative because they are highly dependent on vessel speed, type of engine, sound propagation conditions, as well as the types of algorithms employed for detection and analysis. The best that can be done here is to characterize the background noise and sound propagation so that estimates can be made regarding the sound level at the sensor for a given source level and range.

The first requirement is met because the data is sampled at a rate of $8 \mathrm{kHz}$. The remainder of this chapter addresses the other requirements. Throughout this chapter, spectrograms were produced with the parameters given in Table 3.1 .

\subsection{System Calibration}

Calibration is important because it allows recorded voltages to be converted to sound pressure, a universal measure that is independent of a particular sensor. It is also important to verify that the sensitivity of the sensing system is appropriate for the range of expected measurements - if the system is too sensitive then saturation occurs, and if the system is not sensitive enough then signals are missed. The system was calibrated using a Lubell 9162 underwater speaker (see Figure 3.1). The speaker was first deployed off the dock at a depth of about 2 meters. A series of test signals was generated by driving the speaker at a known input voltage and and frequency for a period of $30 \mathrm{sec}$. The sound pressure (SP) of each emitted test signal was calculated using

Table 3.1. Spectrogram parameters.

\begin{tabular}{cc} 
Parameter & Value \\
\hline window size & $4 \mathrm{sec}$. \\
window overlap & $3 \mathrm{sec}$. \\
time resolution & $1 \mathrm{sec}$. \\
frequency resolution & $0.25 \mathrm{~Hz}$
\end{tabular}



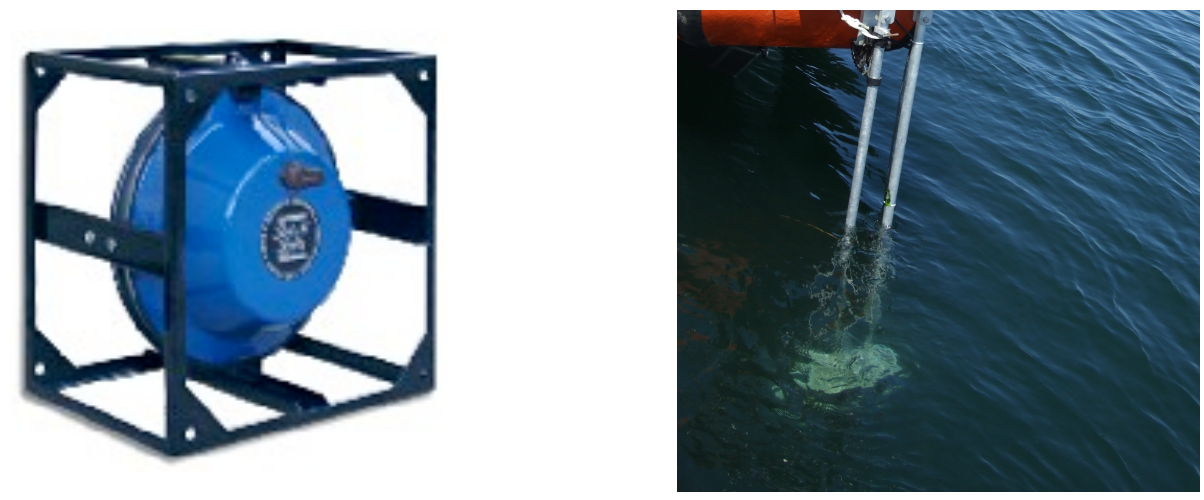

Figure 3.1. The Lubell 9162 underwater speaker was used to generate test tones. The photo on the right shows the speaker deployed off the bow of the SAFE boat at a depth of about 1.5 meters.

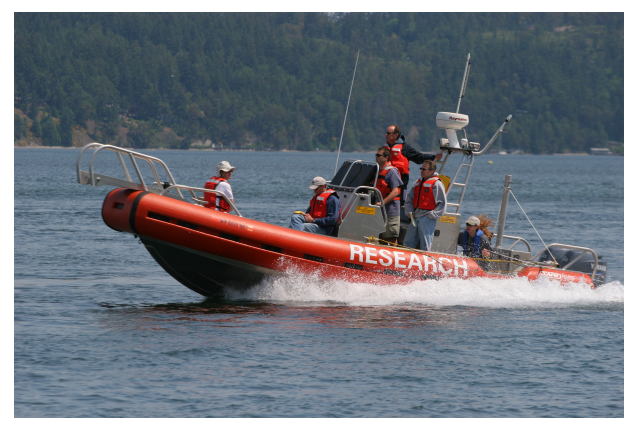

$\begin{aligned} \text { Vessel Type: } & \text { SAFE } \\ \text { Length: } & 23 \mathrm{ft} \\ \text { No. of Engines: } & 2 \\ \text { Engine Type: } & 4 \text {-stroke, } \\ & \text { Yamaha } 100 \\ \text { Prop: } & 3 \text { blades }\end{aligned}$

Figure 3.2. PNNL research vessel used for test.

the manufacturer's specifications for the Lubell's transmit voltage response (TVR),

$$
\mathrm{SP}=V_{\text {in }} \times 10^{\mathrm{TVR}(f)} \quad(\mu \mathrm{Pa}) .
$$

The raw recorded data corresponding to the test tone times was converted into voltage values in the range $[-1010]$. Then the data was transformed into the time-frequency domain as a spectrogram. A visual inspection of the spectrogram deemed whether the recorded tone was clean or corrupted by broadband noise from a passing vessel. Only clean data was used (see Figure 3.3). Then the receive voltage response (RVR) was calculated as

$$
\mathrm{RVR}=20 \log _{10}\left(\frac{V_{\mathrm{rcv}}}{\mathrm{SP}}\right) \quad(\mathrm{dB} \text { re } 1 \mathrm{~V} / \mu \mathrm{Pa}) .
$$

where $V_{\mathrm{rcv}}$ is the average voltage level over the time that the tone was present. The results of the calculations for each of the test tones is given in Table 3.2.

The RVR of the system was found to be $-178 \mathrm{~dB}$ re $1 \mathrm{~V} / \mu \mathrm{Pa}$, which is an appropriate sensitivity for recording the signals from small vessels. The manufacturer specification for the Benthos AC-1 hydrophone is $-201 \mathrm{~dB}$ re $1 \mathrm{~V} / \mu \mathrm{Pa}$ at $20 \mathrm{C}$ water temperature, constant over $1 \mathrm{~Hz}$ to 10 $\mathrm{kHz}$. Since the signal conditioning board has $20 \mathrm{~dB} / \mathrm{V}$ gain and the preamp has $26 \mathrm{~dB} / \mathrm{V}$ gain, this means that the hydrophone itself has a sensitivity of about $-219 \mathrm{~dB}$ re $1 \mathrm{~V} / \mu \mathrm{Pa}$. Possible 
explanations for the discrepency is that the water in Sequim Bay is considerably colder than 20 $\mathrm{C}$, probably closer to $8-10 \mathrm{C}$, and the rubber tubing enclosing the hydrophone may be attenuating the received signal.

\subsection{Background Noise}

The primary noise source is a pump inlet that runs continuously just south of the dock where the hydrophone is deployed. During a recent test, the pump was turned off for approximately 30 minutes so that its effect on the hydrophone data could be analyzed. A spectrogram of the time before and after the pump was turned off is shown in Figure 3.4; the pump generates a slight increase in spectral level across the measured frequency band and also produces strong tonals at $240 \mathrm{~Hz}$ and the first two harmonics.

Other noise sources are wave action against the dock pilings and seawall, and strong tidal currents. During periods of strong tidal flow, when current moves as fast as $1.5 \mathrm{~m} / \mathrm{s}$, or approximately 3 knots, the acoustic data can contain narrow time duration broadband noise. In Figure 3.5. spectrograms from 23 July 6:00 (peak flow) and 23 July 12:00 (low flow) illustrate the effect of the current on the hydrophone data. Both spectrograms contain the signal of a passing vessel; even during the time of strong current flow when the data is noisy, the levels of the vessel's tonals are still above the noise.

To fully characterize the background noise, a more extensive study is needed. The noise is nonstationary, which is typical in a near-shore marine environment. However, it is concentrated in the lower frequencies and does not pose an obstacle to using the acoustic data for the purposes of vessel detection and signature analysis. In fact, the presence of the noise provides a realistic test bed for algorithm development.

\subsection{Underwater Sound Propagation}

Underwater sound propagation is affected by many factors, including the shape and composition of the bottom, water temperature and salinity. Our underwater sensor is deployed about 6 meters off the dock at PNNL-Sequim at a mean depth of approximately 7 meters. The local water

Table 3.2. Calibration Test Results

\begin{tabular}{|r||r|}
\hline Tone (Hz) & $\begin{array}{r}\text { RVR } \\
(\mathrm{dB} \mathrm{re} 1 \mathrm{~V} / \mu \mathrm{Pa})\end{array}$ \\
\hline 200 & -186 \\
500 & -168 \\
1000 & -189 \\
1500 & -168 \\
2000 & -176 \\
\hline Average & -178 \\
\hline
\end{tabular}



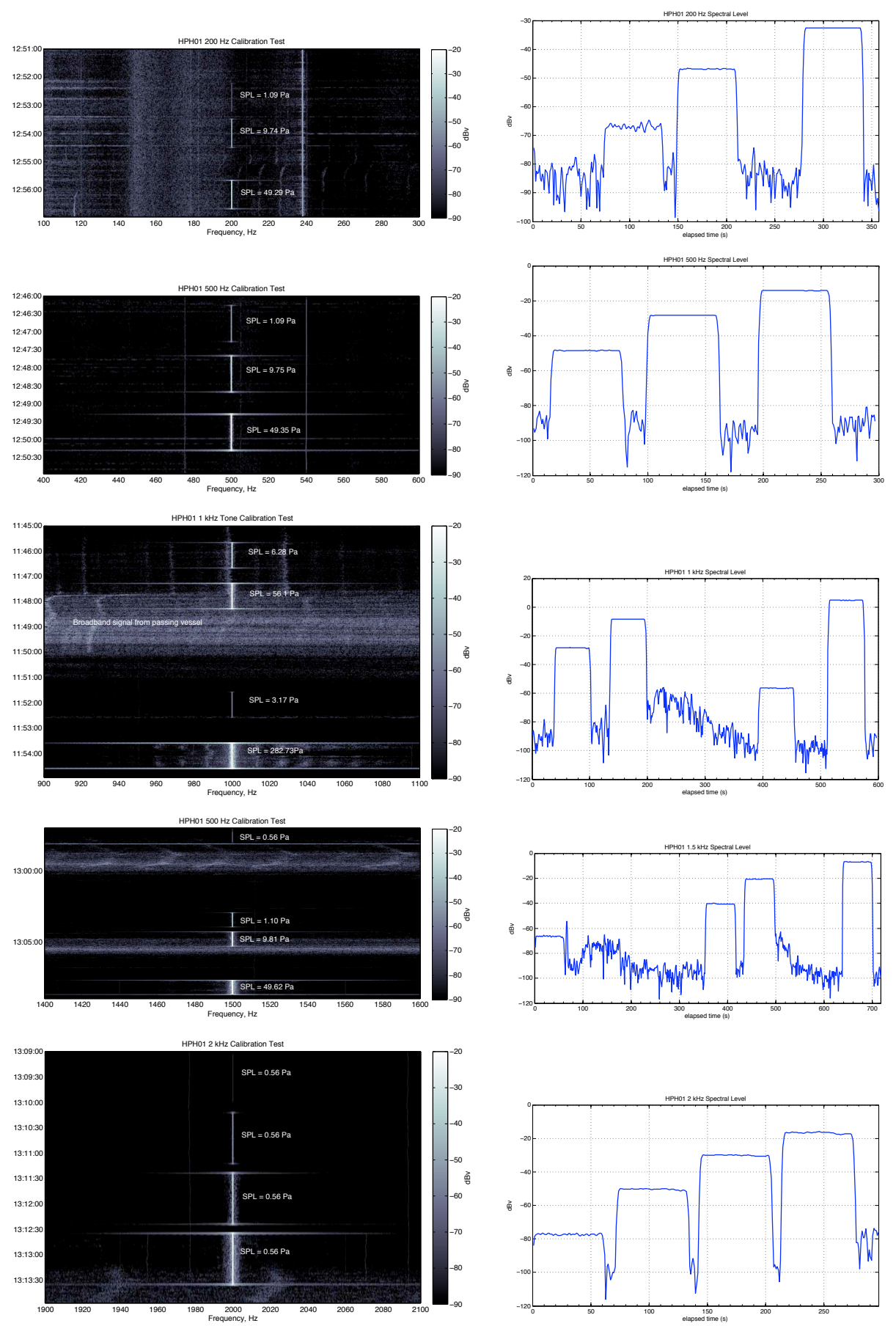

Figure 3.3. Calibration test data. The plots on the right show a single column of the spectrogram on the left, where the column corresponds to the frequency of the test tone. The portions of the data to use for the calibration were selected by visual inspection of these plots to identify where the level of the tone was fairly constant. 

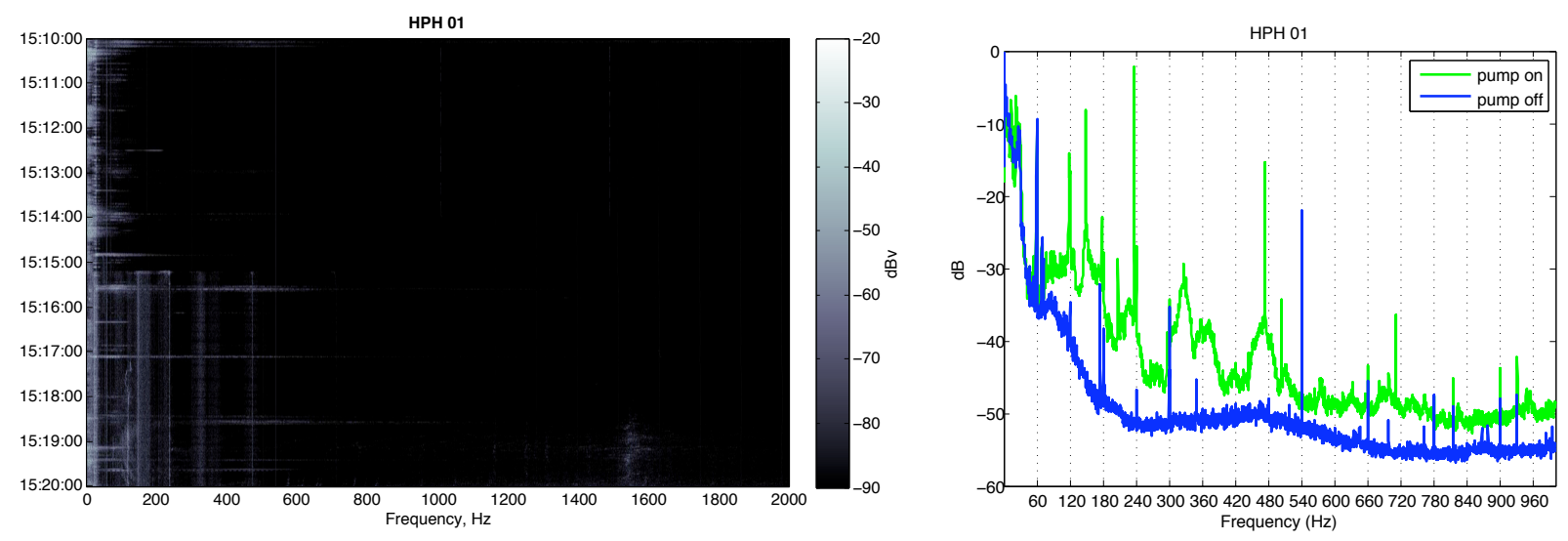

Figure 3.4. The plot on the right is a full FFT of the hydrophone recording from 15:10 to 15:14 (pump off) and from 15:16 to 15:20 (pump on). There appear to be tones at approximately 240,480 , and $720 \mathrm{~Hz}$ due to the pump.

depth and landmass features can be seen in Figure 3.6 the principal being Travis spit which juts westward forming the northern boundary of Sequim Bay. All vessel traffic into and out of the bay, therefore, travels around the end of the spit and passes within $0.5 \mathrm{~km}$ of the sensor.

Acoustic underwater signal attenuation is modeled as spreading and absorption. As a sound wave travels over distance, the energy it contains spreads out in all directions (spherically). The spreading will be more cylindrical when it is limited by the water surface and/or bottom as in shallow waterways. Absorption is the loss of energy due to conversion into heat; this loss is only significant for very high frequency sound.

The model for transmission loss (TL) is

$$
\mathrm{TL}(f, r)=\beta(r)+\alpha(f, T, S) r \quad \mathrm{~dB},
$$

where $\beta$ is the spreading function, $\alpha$ is the absorption term, $f$ is frequency, $r$ is distance in meters, $T$ is water temperature in $\mathrm{C}$, and $S$ is salinity in ppt.

The spreading function can be spherical, cylindrical or a mixture of the two. For this location, the fairly shallow water depth (see Figure 3.7) indicates that the cylindrical spreading model is most appropriate for distances greater than about 12 meters (two times the average water depth). The contribution of the absorption term for distances less than 10 kilometers is negligible relative to the spreading term, and so can be ignored here. The transmission loss model is then

$$
\mathrm{TL}(r)=10 \log _{10}(r)
$$

The data segment used for the transmission loss analysis was generated by the SAFE boat towing the Lubell speaker away from the hydrophone along the track shown in Figure 3.7. The source range from the hydrophone increased from about 10 to 170 meters. The transmission loss analysis results are shown in Figure 3.8 which plots the measured signal strength vs. range along with the model predicted values for cylindrical spreading. The measured data agrees reason- 

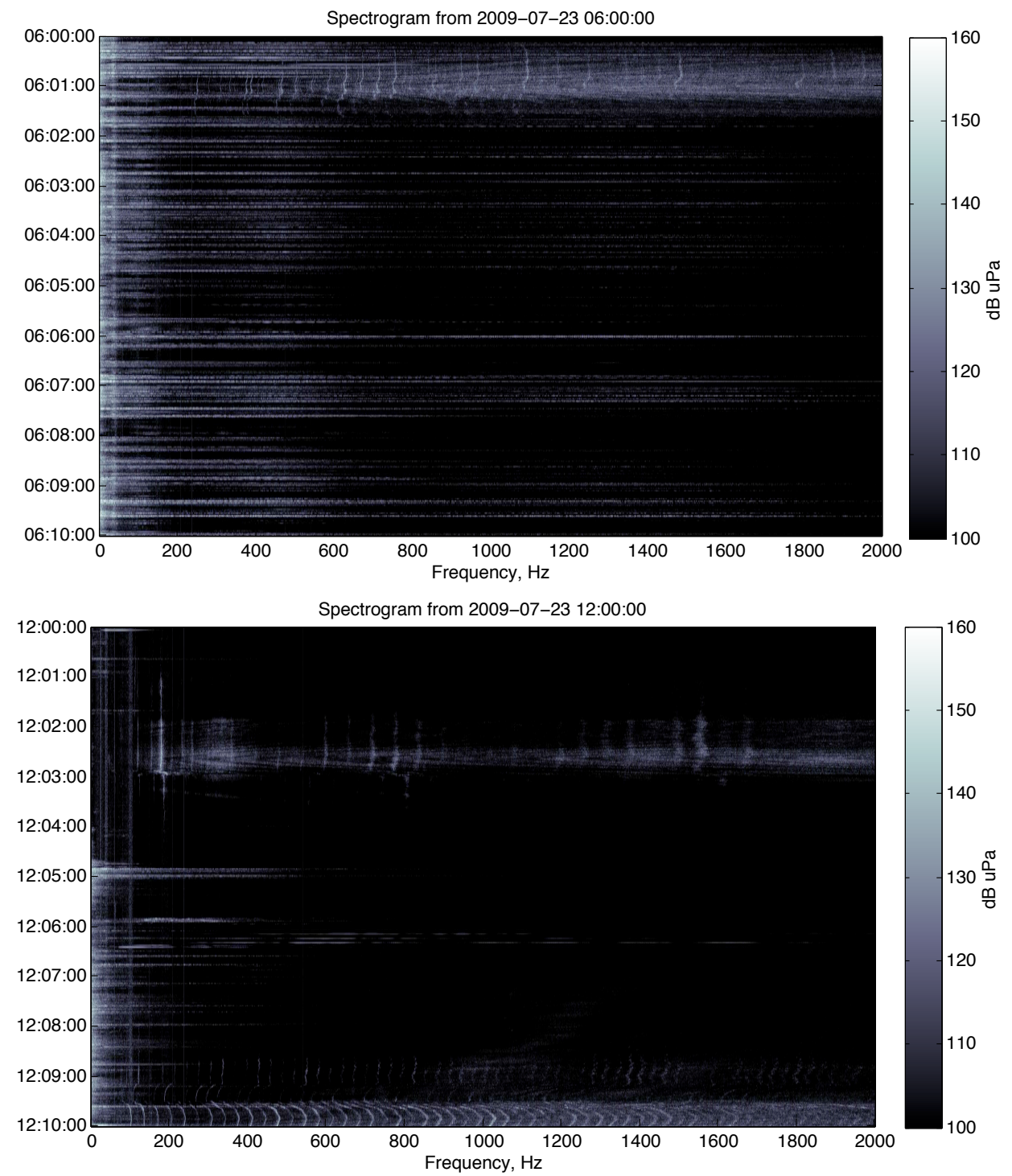

Figure 3.5. The upper spectrogram is from a time when the tidal current was at its peak; the lower spectrogram is from later the same day when the current was weaker. The signal of a passing vessel is evident between 6:00 and 6:01, and between 12:02 and 12:03. 


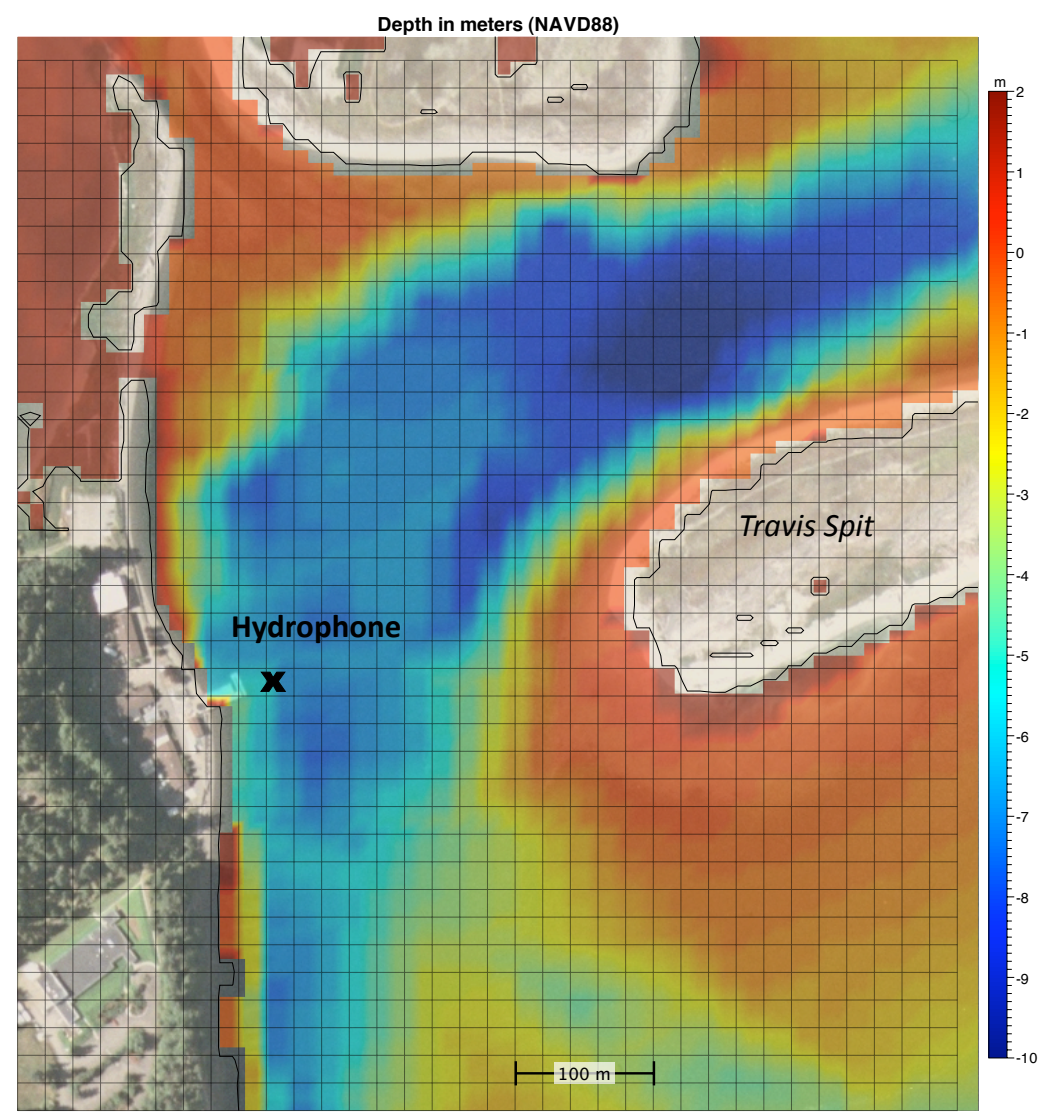

Figure 3.6. The water depth and land masses of the area surrounding the underwater sensor.

ably well with the model, although the level seemed to fall off a bit more quickly than the model after about 80 meters. This could be due to deviations in the actual boat track from the planned course.

\subsection{Detection Range}

To estimate the detection range of a vessel with a given sound pressure, a minimum detectable signal must first be defined. Based on empirical evidence produced by applying a detection algorithm to the NW MILO data, the signal at the receiver must be at least $100 \mathrm{~dB} \mu \mathrm{Pa}$. So the detectable range as a function of source level, using the cylindrical spreading model, is

$$
\begin{aligned}
S_{\min } & =\mathrm{SL}_{\mathrm{src}}-10 \log _{10}\left(r_{\max }\right) \\
100 & =\mathrm{SL}_{\mathrm{src}}-10 \log _{10}\left(r_{\max }\right) \\
10 \log _{10}\left(r_{\max }\right) & =\mathrm{SL}-100 \\
r_{\max } & =10^{(\mathrm{SL}-100) / 10}(\mathrm{~m})
\end{aligned}
$$

Our data contains instances of a small vessel with an outboard engine that produces a signal around $126 \mathrm{~dB} \mu \mathrm{Pa}$ at the sensor. If the distance of the vessel from the sensor was $200 \mathrm{~m}$, then the source level of the vessel is between $140 \mathrm{~dB} \mu \mathrm{Pa}$, factoring in the TL over $200 \mathrm{~m}$. Then such 
Source Track
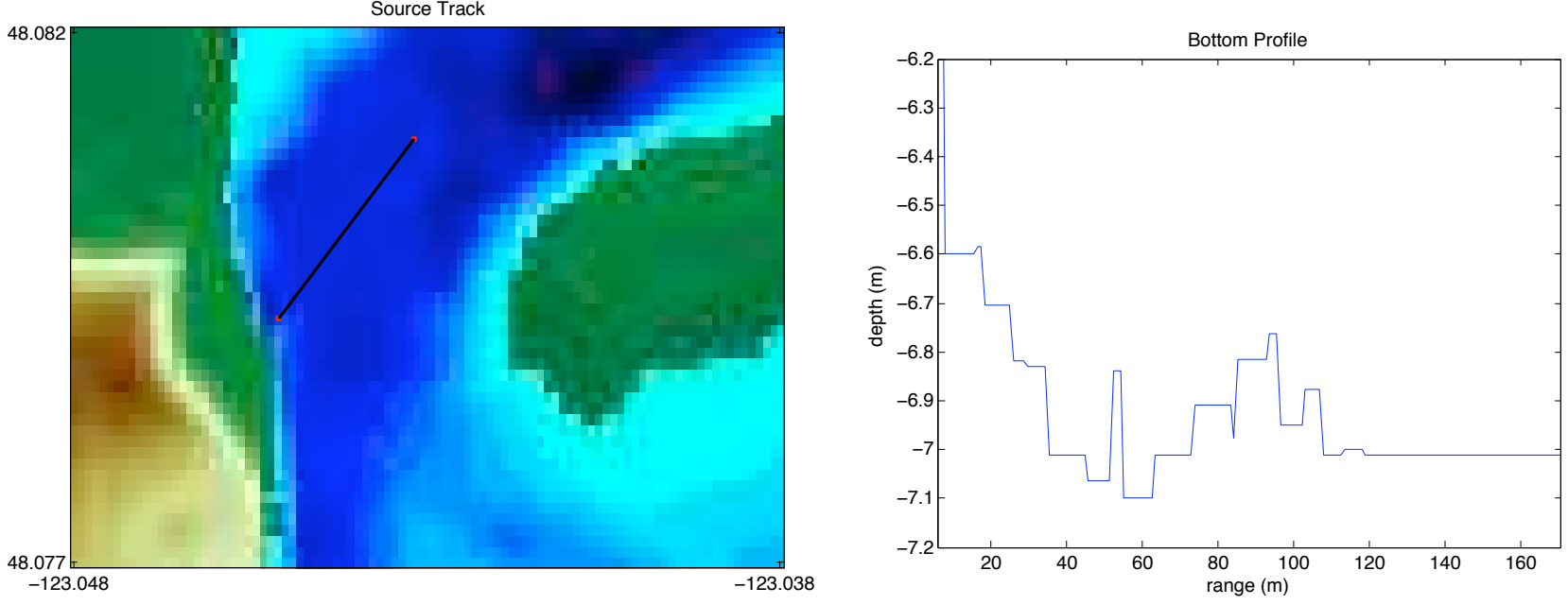

Figure 3.7. The map on the left shows the approximate track of the research vessel towing the speaker for the transmission loss test. The plot on the right shows the bottom profile along the track.

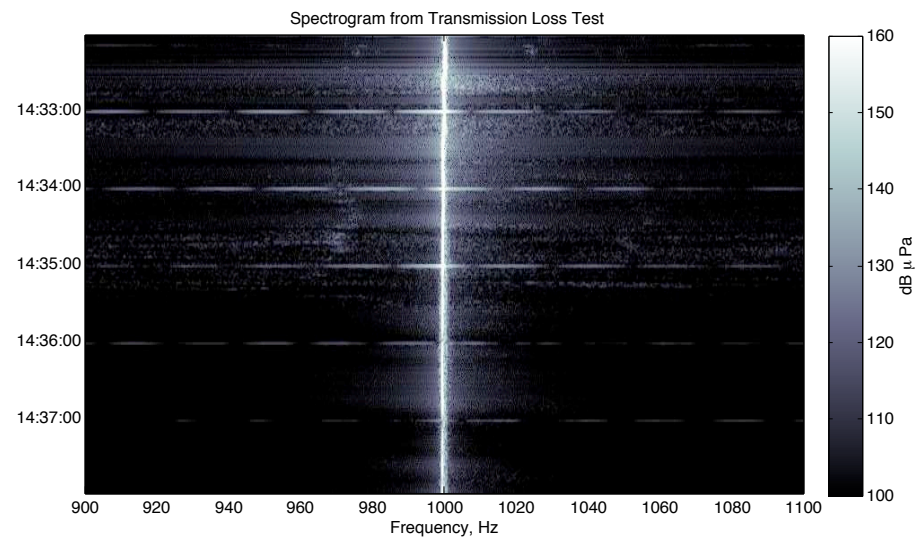

a.

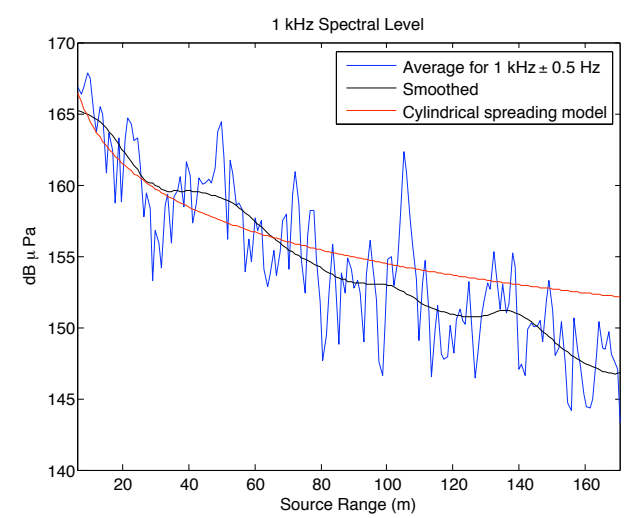

b.

Figure 3.8. Short range transmission loss analysis. a) Spectrogram of $1 \mathrm{kHz}$ test signal from speaker being towed away from the sensor. A significant amount of broadband noise is evident in the test time segment which may be due to the vessel towing the speaker. b) Plot of the amplitude of the the test signal vs. distance from sensor. The measured transmission loss agrees fairly well with the cylindrical spreading model. The deviation from the model could be due to imprecise source distance estimation. 
a vessel is theoretically detectable from a distance of

$$
r_{\max }=10^{(140-100) / 10}=10 \quad(\mathrm{~km})
$$





\subsection{Conclusions and Discussion}

The NW-MILO acoustic data collection has been evaluated in terms of sensor sensitivity, background noise levels and transmission loss. The sensor sensitivity was found to be acceptable for the purposes of recording the acoustic signals of small vessels, given the average background noise level and transmission loss model. Due to the location of the sensor, the passing vessels are within 500 meters and at this range the vessel signals are detectable. There is a constant background noise level due to a nearby pump, and additional noise that varies with the tidal current. Both these noise sources could possibly be attenuated by relocating the sensor to the northwest of the dock, further from the pump and out of the main tidal flow. A better solution would be to keep the sensor in its present location, and deploy a second sensor in the northwest location. This would facilitate a more refined characterization of the noise, as well as allow for combining the output of both sensors to produce a higher SNR vessel signature.

Despite the background noise, the quality of the data collection is more than adequate for signature analysis and other applications, such as acoustic trigger development and classification.

The acoustic data will continue to be collected, along with radar tracks and video imagery. To complement the local data, a mobile platform is being prepared for collecting data at other locations. This data will then be added to the current repository in the same format as the local data, and will increase knowledge about environmental factors that affect vessel signatures.

The vessel signature analysis will continue to be refined. At this point, it is not clear exactly what information about a vessel can be reliably extracted from the acoustic signal, and how this information can best be represented for the purposes of classification. Future tests using PNNL's research vessels are planned to investigate how boat speed, direction of travel and distance from the sensor affect the acoustic signal of a particular vessel. 



\section{Appendix A}

\section{Data Acquisition System Schematic}





\section{Appendix A - Data Acquisition System Schematic}

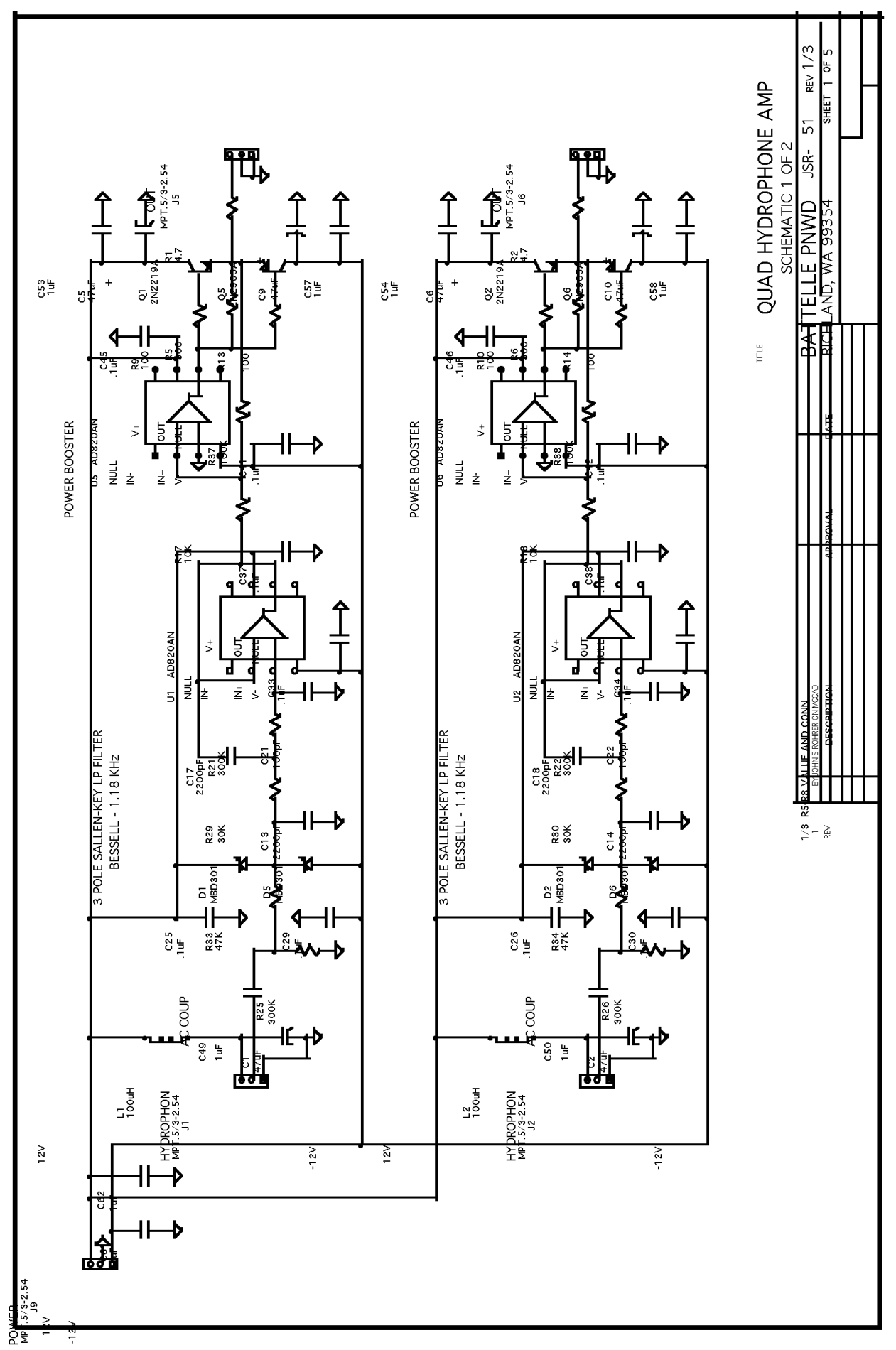




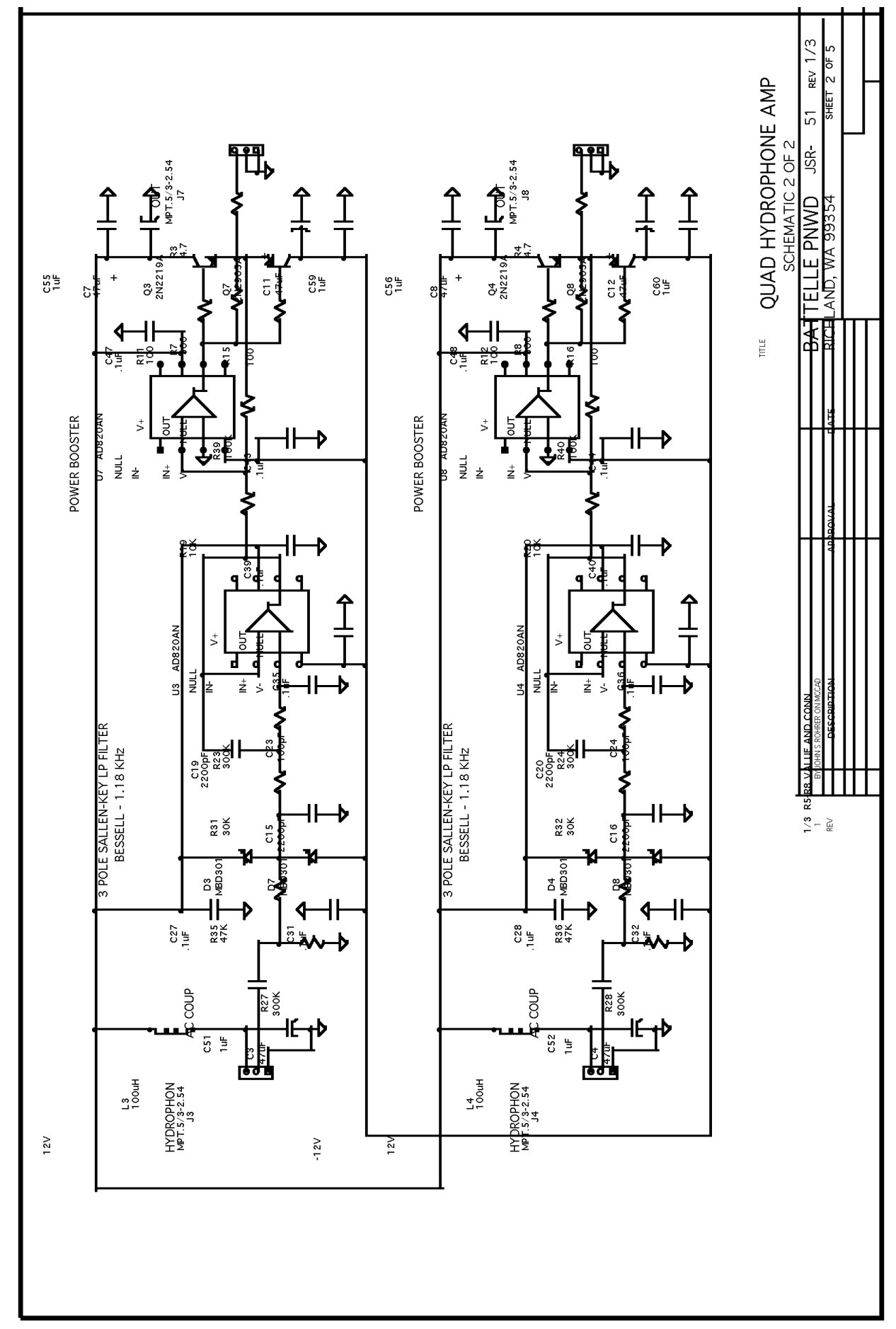




\section{Appendix B}

\section{Data File Formats}





\section{Appendix B - Data File Formats}

The raw acoustic data is stored in binary files, with each file containing 10 minutes worth of data. The values are raw 16-bit unsigned integer values output by the data acquisition board. Each file contains header information that includes the sampling rate, the voltage range for converting the values to volts, etc. The details are given in Table B.1.

The raw data files are then used to create netCDF file containing the data and meta-data that describes the collection location. This format is described in Table B.2.

Table B.1. Raw Data File Format

\begin{tabular}{|c|c|c|l|}
\hline Position & Size (bytes) & Type & \multicolumn{1}{|c|}{ Description } \\
\hline 0 & 8 & unsigned int & $\begin{array}{l}\text { Time of the first sample as seconds } \\
\text { from Jan. 1, 1970. }\end{array}$ \\
\hline 8 & 4 & long & $\begin{array}{l}\text { Sampling rate in Hz. } \\
\text { Voltage range; e.g. if this value is } \\
\text { 10, then the range is } \pm \text { 10. }\end{array}$ \\
\hline 12 & 4 & float & $\begin{array}{l}\text { First channel scanned, channels are } \\
\text { indexed from 0 to 7. }\end{array}$ \\
\hline 16 & 4 & int & $\begin{array}{l}\text { Last channel scanned. } \\
\text { Channel source name, 5 chars per } \\
\text { channel; only the names correspond- } \\
\text { ing to the channels scanned are valid. }\end{array}$ \\
\hline 20 & 4 & int & $\begin{array}{l}\text { Data; the data is written in sample } \\
\text { order, i.e. the first sample from the } \\
\text { first channel followed by the first } \\
\text { sample from the second channel, etc. }\end{array}$ \\
\hline 64 & to EOF & 16-bit unsigned integer &
\end{tabular}

B. 1 
Table B.2. netCDF Data File Format

\begin{tabular}{ll}
\hline & \multicolumn{1}{c}{ Dimensions } \\
\hline time & (unlimited) sample index \\
time:title & variable label string \\
time:units & "seconds" \\
time:start_utc & date time string \\
time:start_posix & number of seconds since Jan. 1 1970 0:00 \\
time:start_posix_units & "seconds" \\
\hline & \multicolumn{1}{c}{ Variables } \\
\hline HPH01 & 16-bit scaled data \\
HPH01:title & variable label string \\
HPH01:units & "scaled volts" \\
\hline & Global Attributes \\
\hline tz_offset & local timezone offset from GMT \\
tz_offset_units & "hours" \\
site & string for location where data was recorded \\
latitude & degrees lattitude of sensor \\
longitude & degrees longitude of sensor \\
nominal_sampling_rate & expected sampling rate \\
sampling_rate & calculated sampling rate \\
sampling_rate_units & "Hz" \\
voltage_range & analog-digital conversion input range \\
voltage_range_units & "volts" \\
&
\end{tabular}




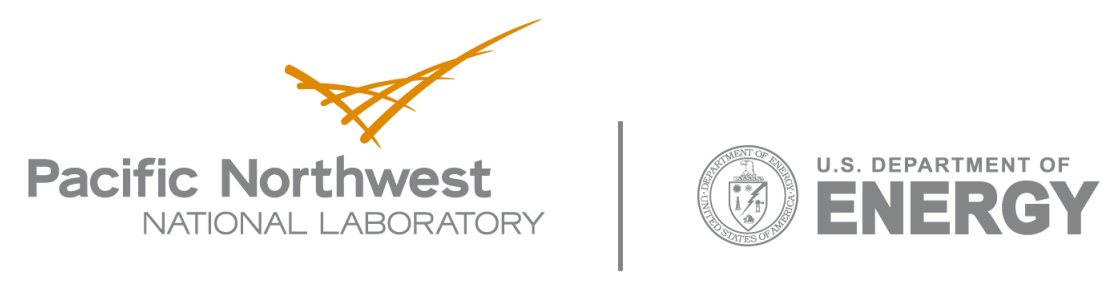

902 Battelle Boulevard

P.O. Box 999

Richland, WA 99352

1-888-375-PNNL (7665)

www.pnl.gov 